\title{
Investigation of the ecological component of the urban environment quality based on the available spatial data
}

\author{
Anna A. Gosteva ${ }^{1,2}$, Sofja P. Ilyina ${ }^{2}$ and Aleksandra K. Matuzko ${ }^{1}$ \\ ${ }^{1}$ Institute of Computational Modelling of the Siberian Branch of the Russian Academy of Sciences, Krasnoyarsk, Russia \\ ${ }^{2}$ Siberian Federal University, Krasnoyarsk, Russia
}

\begin{abstract}
The city is a complex system in which all components of the ecosystem interact with each other. In the course of the constant collection of information about the ecological situation, significant amounts of data are accumulated, the combination of which in a single information space provides new opportunities for obtaining new knowledge about the study area.

The paper presents a study of the ecological component of the urban environment quality on the example of Krasnoyarsk city using open spatial data. Since one of the main factors for the assessment is the natural and ecological situation in the city, the following quality indicators were selected: the nature of thermal anomalies, air and land surface temperature, relief, number of storeys of residential and industrial buildings, concentration of suspended particles. The data on the land surface temperature were prepared using the Landsat-8 satellite data from 2013 to 2020, cloudless scenes were selected during the snowless period, which amounts to 30 scenes per city territory. The Open Street Map database was used to determine the number of storeys and types of all city structures.

To achieve the goals, the authors selected the necessary vector layers for analyzing the urban environment, carried out a search and download of data on the air temperature and the land surface temperature, organized a single information space for geoinformation analysis across the Krasnoyarsk city.

As a result of the geoinformation analysis, the search for relationships between objects was carried out, a comparison of data on one indicator from different monitoring sources was made. A vector polygonal layer has been created from small segments on the territory of the city that are more homogeneous in terms of buildings and relief features to search for relationships. Sets of layers where seasonal thermal urban anomalies are displayed have been created, the ratio of stable elevated temperatures to local climatic zones has been found, and existing sources have been evaluated regarding assessment of atmospheric air in relation to stable heat islands.
\end{abstract}

\section{Keywords}

Thermal space images, Landsat, earth surface temperature, urban climate.

\section{Introduction}

The city is a complex system in which all components of the ecosystem interact with each other. In the course of the constant collection of information about the ecological situation,

SDM-2021: All-Russian conference, August 24-27, 2021, Novosibirsk, Russia

@agosteva@icm.krasn.ru (A. A. Gosteva)

(c) (1) $\odot 2021$ Copyright for this paper by its authors. Use permitted under Creative Commons License Attribution 4.0 International (CC BY 4.0).

[eEUR Workshop Proceedings (CEUR-WS.org) 
significant amounts of data are accumulated, the combination of which in a single information space provides opportunities for obtaining new knowledge about the study area.

The research is carried out on the territory of Krasnoyarsk city. Krasnoyarsk is located on both banks of the Yenisei River in its middle reaches. The river valley plays an important role in the formation of the landscape features of Krasnoyarsk city. It is a strip of transitional landscapes between large natural zones and occupies the predominant part of the city [1].

The article describes the complex application of the land surface temperature (LST), air temperature and thermal anomaly data. Landsat- 8 satellite images serve as the source of spatial data on the LST, and information on air temperature was obtained from the air monitoring system of the Federal Research Center "Krasnoyarsk Scientific Center of the Siberian Branch of the Russian Academy of Sciences" (FRC KSC SB RAS). An integrated approach to the study of the urban ecosystem will help to assess the current state of the environment and assess the sites with the greatest environmental stress.

Particular attention is paid to the objects of industrial emissions, in particular the pipes of industrial enterprises and boiler houses, which make a significant contribution to the deterioration of the ecological situation in the city. For Krasnoyarsk, the stability of the wind regime is characteristic throughout the year, which is explained by the conditions of orography. In this case, the direction of the Yenisei valley coincides with the prevailing wind direction. The width of the Yenisei valley within the city changes sharply, which affects the speed of the wind flow and, as a consequence, the intensity of ventilation of the territory. In the place where the river leaves the mountains of the Eastern Sayan, the valley expands to a large extent, reducing the average wind speed [2]. In the repeatability of wind directions and calmnesses occurrence along 16 points, it is obvious that the winds of three points prevail during the year: west - south-west; west; west - northwest [3].

\section{Materials and methods}

The effect of an increase of ambient temperature is observed in large cities, where the air temperature throughout the year is several degrees higher than outside its borders. The observation that the air temperature in the city is higher than the temperature of the surrounding area was discovered in 1810 by Luke Howard, and received the name of the urban heat island [4].

Built-up areas appear as irregular artificial landscapes with building materials partly different from natural surfaces. In addition, anthropogenic processes generate excess heat and pollute the environment. Together they affect the air temperature inside the city, and it becomes higher than outside. The LST is also one of the indicators of the greenhouse effect and anthropogenic impact on natural resources [5].

The work is aimed at studying the heat islands of Krasnoyarsk city. Krasnoyarsk is a large industrial center with unique natural and climatic features caused by relief conditions and thermal heterogeneity of the area. The construction of the Krasnoyarsk hydroelectric power station led to non-freezing of the river within the city limits during the cold season. The air temperature in winter reaches values below $-30{ }^{\circ} \mathrm{C}$, and in summer it rises above $30^{\circ} \mathrm{C}$, while the water temperature remains around $5-7^{\circ} \mathrm{C}$. The interaction of these thermal effects negatively affects the ecological situation of the city [6]. 
The ground-based observation network of the Federal Research Center of the KSC SB RAS currently has 21 CityAir air monitoring stations developed by a group of companies from the Novosibirsk Technopark and the Skolkovo Innovation Center. For a large million-person city, the coverage of such a network is insufficient and does not provide full coverage, therefore it is so important to search for alternative methods of obtaining information, for example, using satellite remote sensing data with the ability to calculate LST.

\section{Calculation of LST}

The fund of space imagery materials in the thermal infrared range has been accumulating since the 1960s. The collected archive of images makes it possible to analyze the changes that have occurred on the Earth for more than 60 years [7]. Technologies for obtaining information by remote methods have been improved, the quality of spatial and temperature resolution has increased. In February 2013, the launch of the modern satellite Landsat-8 took place, the data is presented on the online service (https://www.earthexplorer.usgs.gov), which receives data using two different sensors - Operational Land Imager (OLI) and Thermal Infrared Sensor (TIRS). The TIRS scanner was created at NASA's Goddard Space Flight Center and is designed to provide far infrared (IR) imaging. In the focal plane of the TIRS, GaAs-based Quantum Well Infrared Photodetector (QWIP) photosensors are installed [8]. The TIRS thermal range scanner captures in two bands 10.6-11.2 microns (band 10) and 11.5-12.5 microns (band 11) with a spatial resolution of $100 \mathrm{~m}$, which makes it possible to analyze the energy of the earth's surface itself, not the reflection of sunlight. The values of the heat bands can be used to determine the LST. The surface of the earth, due to its heterogeneity, has a different emissivity, which is determined by the emission factor. Meteorological stations measure the air temperature 2 meters above the ground, and using satellite systems, the LST is calculated directly. Theoretically, the accuracy of the temperature estimate is about $0.5{ }^{\circ} \mathrm{C}$, however, the atmospheric haze leads to underestimation of LST values by several degrees (http://www.wiki.gis-lab.info/w/Correction materials_Landsat). Work on studying the LST has been carried out for the last few years, and during this time several options for calculating the LST for Landsat- 8 data have been investigated, which are described in detail in other works of the authors [9]. QGIS software was used for all calculation.

\section{Outlining perennial urban heat islands}

Materials for studying the urban heat island were collected from the Landsat- 8 satellite imagery archive from 2013 to 2020. More than 30 scenes were collected from the snowless period. For each scene, a separate heat island was formed using a technique consisting of the following steps.

1. Calculate the LST according to Landsat-8 data.

2. For each calculation, determine the min, max, average value.

3. Determine the range of maximum values for each scene

4. Convert raster cells from the range of maximum values to vector data format

5. Combine the resulting vector polygons

6. Remove polygons less than $2500 \mathrm{~m}^{2}$. 
The perennial urban heat island outlining was performed for three seasons: spring, summer, and autumn. Since it has been observed that seasonality affects the distribution of the urban heat island. Therefore the robustness and instability of temperature anomalies was evaluated by that principle.

The urban heat island is characterized in many works as a negative consequence of the development of large cities and industry, for this reason it is interesting to evaluate the city territory using climatic zoning.

\section{Local climatic zones of the city}

Local climatic zones - areas with a uniform surface coverage, structure, materials and a special nature of human activity, which have a special type of interaction with the surface layer of the atmosphere. Outlining of local climatic zones in cities makes it possible to reduce various combinations of buildings and land cover to a limited number of classes that can be used to unify observation sites for an urban heat island, as well as to be used in problems of climatic and meteorological modeling [10].

In this article, a method for identifying local climatic zones is used, which takes into account the type of building and the type of underlying surface. For the zoning of the city, characteristics such as building density and the height of structures were chosen.

The application of this method was used in the work of Samsonov T.E. and Triguba K.S. "Mapping the local climatic zones of Moscow using space images" local climatic zones are identified using space images. Unlike the work of Samsonov T.E. and Triguba K.S., local climatic zones in Krasnoyarsk city were distinguished manually based on vector data from the Open Street Map project and the number of local climatic zones was reduced to three, since the selected types of development are the most relevant for Krasnoyarsk city and significantly affect the redistribution of air flows in the atmospheric air of Krasnoyarsk city. (In the work "Mapping the local climatic zones of Moscow using space images" local climatic zones are identified using space images).

For Krasnoyarsk city, the predominant types of development are: the private sector, largescale buildings and heavy industry, and residential areas. It was decided to reclassify the local climatic zones proposed by Stuart I.D. and Oke T.R. for the relevance of their application for studying the territory of Krasnoyarsk city. Types of local climatic development zones proposed by Stuart I.D. and Oke T.R. namely, compact high-rise buildings, compact mid-rise buildings, open high-rise buildings and open mid-rise buildings have been combined into residential quarters, compact low-rise buildings, scattered and open low-rise buildings have been combined into the private sector, large-sized low-rise buildings and heavy industry has also become one type.

Also, the methods of microclimatic zoning of the territory of Krasnoyarsk city are described in the works of Mokrints K.S., but in his works zoning was carried out according to the geomorphological features of the relief of the territory of Krasnoyarsk city, and in this article microclimatic regions are distinguished by the type of the prevailing type of building. 


\section{Results}

By combining the LST, the contours of urban heat islands, industrial facilities, air temperature, wind direction, climatic zones, a set of spatial data was formed on the territory of Krasnoyarsk city for a comprehensive study of the ecological situation. Figure 1 shows an example of a dataset as of $05 / 20 / 2020$, where the main underlay represents the air temperature according to the data of the observation stations.

In Figure 2, the main underlay is LST data as calculated by Landsat- 8 on the same date $05 / 20 / 2020$ as in Figure 1. In Figure 2, the rectangle marks the area most interesting for the next consideration.

Figure 3 groups the areas where the air heat island does not coincide with the urban heat island. In addition, the figure shows that the location of meteorological stations does not coincide with the contours of urban heat islands. Figures 3, a and b show the territory of the railway station and mountain Karaulnaya, and the meteorological station is located outside the urban heat island, which leads to a mismatch between the air and the heat island of the land surface. Figures $3 \mathrm{c}$ and $3 \mathrm{~d}$ show the industrial zone of the right bank (Sibtyazhmash, Krastsvetmet, Gazobeton), where the meteorological station is shifted relative to the urban heat island.

When the observation station is located on a heat island, there is an overlap of the ground and air heat islands. A comprehensive study of the city's territory reflects the coincidence of urban heat islands with the location of industry; this principle corresponds to the division of the urban environment by climatic zones. Figure 4 shows an example where an air monitoring station

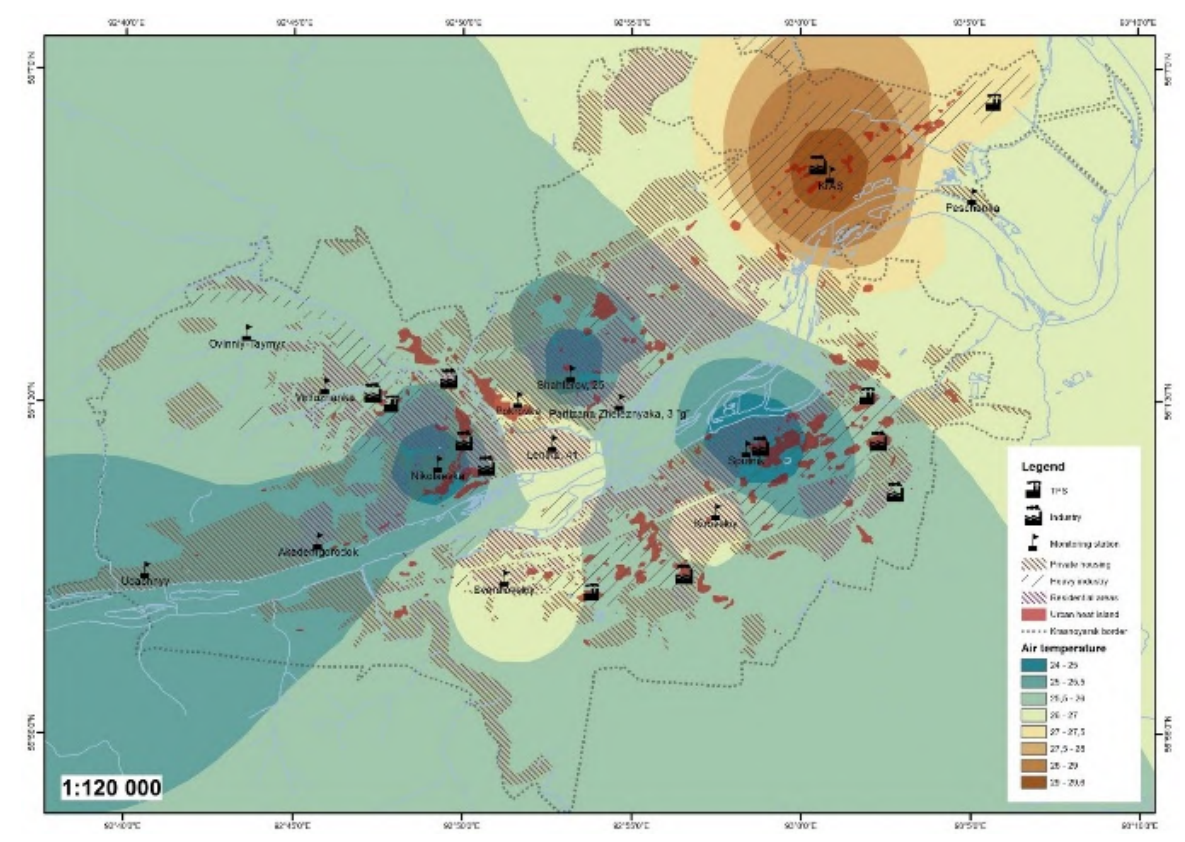

Figure 1: Air temperature of Krasnoyarsk city 05/20/2020 according to the monitoring network of the FRC of the KSC SB RAS. 


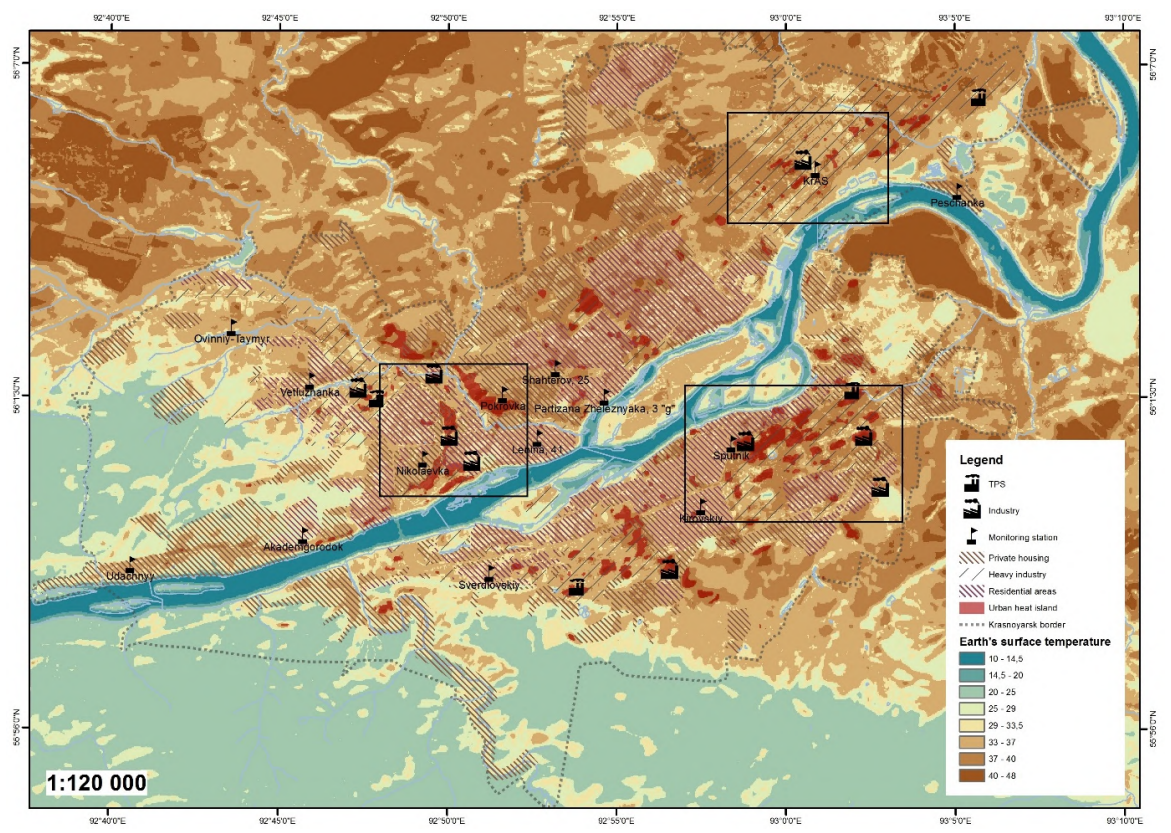

Figure 2: LST of Krasnoyarsk 05/20/2020 according to Landsat-8 data.

a (air temperature map)

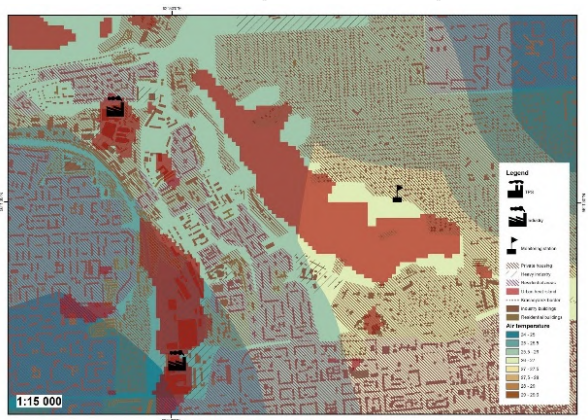

c (air temperature map)

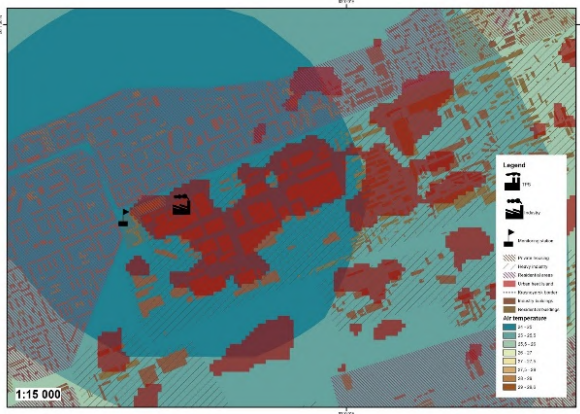

b (map of the LST)

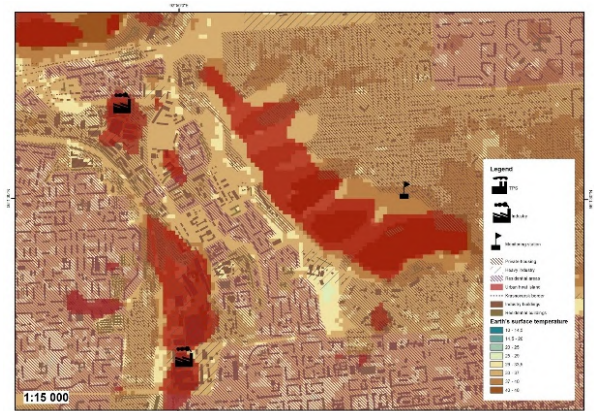

$\mathrm{d}$ (map of the LST)

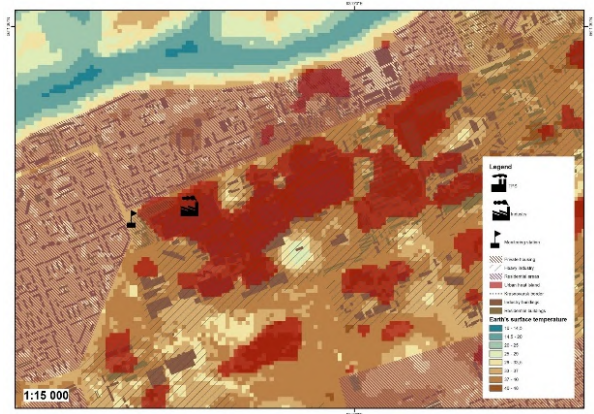

Figure 3: Temperature maps 05/20/2020 for mountain Karaulnaya (a and b) and Sibtyazhmash (c and d). 


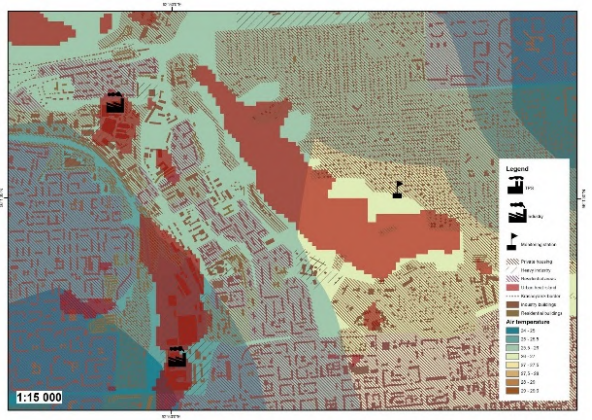

b

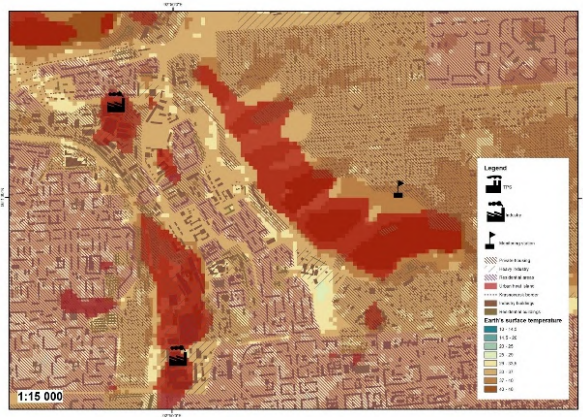

Figure 4: Air temperature map (a) 05/20/2020 and map of the LST (b) for Krasnoyarsk aluminum smelter.

is located in the center of one of the city's heat islands (on the territory of the Krasnoyarsk aluminum smelter). Therefore, when analyzing air temperature, it is important to take into account the location of monitoring stations.

\section{Conclusions}

The features of the thermal properties of the land surface and air temperature are characterized by the geographical features of the territory in which Krasnoyarsk city is located and the urbanization of the territory.

Comprehensive monitoring of the urban environment is a key point in providing information about the environmental situation based on various spatial data. It is very important to use direct and remote data sources and products based on their analysis. It is also important to consider the available spatial data together, taking into account their influence on each other. And the effectiveness of the application of the obtained data depends on the quality of their complex evaluation.

An increase the air and the land temperature is most pronounced in areas of the city with large-size buildings and heavy industry, which is caused by favorable conditions for overheating of the surface. It is important to consider the location of urban weather stations, as this can have an impact when compiling general urban climate characteristics.

Dividing the territory into functional clusters helps to distribute the urban environment in terms of environmental safety.

\section{References}

[1] Antonenko O.V., Bezrukikh V.A., Avdeeva E.V., Nazarova E.I., Kislenko A.M. Landscape features of the city of Krasnoyarsk as a geological and geomorphological basis for urban planning // Conifers of the Boreal Area. Vol. XXXV. No. 1-2. P. 15-20.

[2] Mokrinets K.S. Microclimatic potential of relief of teritory of krasnoyarsk as a condition for formation of quality of the ground layer of atmosphere // The bulletin of the Krasnoyarsk Shtate Pedagogical University after V.P. Astafev. 2011. No. 4. P. 295-300. 
[3] Adjustment of the free volume of maximum permissible emissions for the city of Krasnoyarsk. Available at: http://krasecology.ru/About/PDV (accessed June 24, 2021).

[4] Clinton N., Gong P. Modis detected surface urban heat islands and sinks: Global locations and controls // Remote Sens. Environ. 2013. Vol. 134. P. 294-304.

[5] Asmus V.V., Dyadyuchenko V.N., Makridenko L.A. et al. Ground-based complex for receiving, processing, archiving, and distribution of satellite information // Trudy NITs "Planeta". 2005. No. 1. P. 46.

[6] Khlebopros R.G., Taseiko O.V., Ivanova Yu.D., Mykhaylyut S.V. Ecological essays. Krasnoyarsk: Siberian Federal University, 2012. 130 p. (In Russ.)

[7] Merlin O., Duchemin B., Hagolle O., Jacob F., Coudert B., Chehbouni G., Dedieu G., Garatuza J., Kerr Y. Disaggregation of MODIS surface temperature over an agricultural area using a time series of Formosat-2 images // Rem. Sens. of Env. 2010. Vol. 114. P. 25002512.

[8] Herbert J. Kramer Landsat-8/LDCM (Landsat Data Continuity Mission). Available at: https://directory.eoportal.org (accessed June 24, 2021).

[9] Matuzko A.K., Yakubailik O.E. Urban heat island effects over Krasnoyarsk obtained on the basis of Landsat 8 remote sensing data // IOP Conference Series: Earth and Environmental Science. 2018. Vol. 211. No. 1. Art. no. 012010.

[10] Samsonov T.E., Trigub K.S. Mapping of local climatic zones of Moscow from space images // Geodesy and Cartography. 2018. No. 6. P. 14-25. DOI:10.22389/0016-7126-2018-936-6-14-25. 